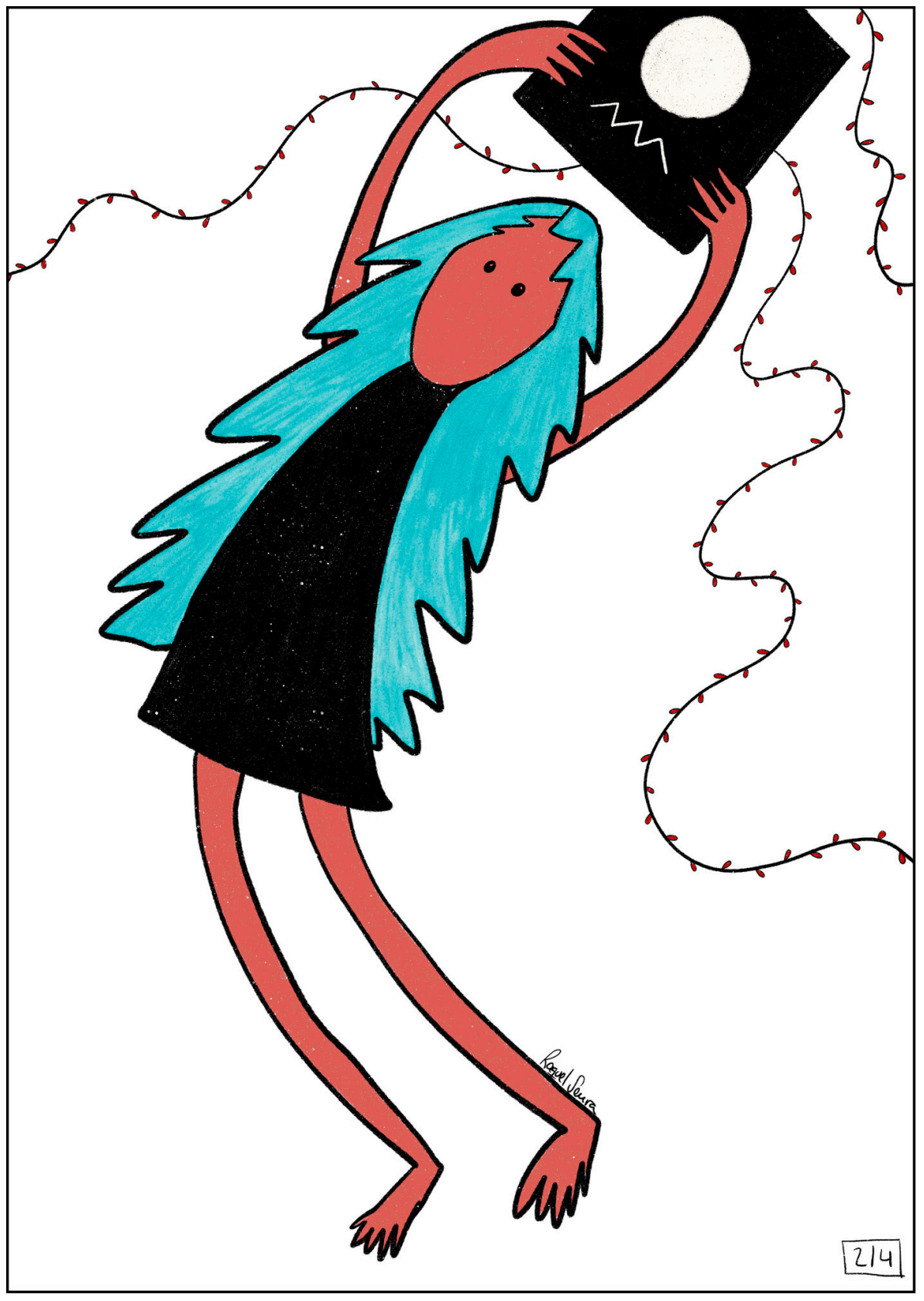


AUTORa: Raquel Senra 


\title{
0 traxe rexional na obra narrativa de Emilia Pardo Bazán
}

\author{
Blanca Paula Rodríguez Garabatos \\ [Recibido, 22 decembro 2019; aceptado, 4 xuño 2020]
}

[Rodríguez Garabatos, B. P. (2020). O traxe rexional na obra narrativa de Emilia Pardo Bazán.

Boletín Galego de Literatura, 56, "Estudos", 5-22]

DOI http://dx.doi.org/10.15304/bgl.56.6475

RESUMO A cultura rural, particularmente a indumentaria, é un elemento narrativo imprescindíbel na obra literaria de Emilia Pardo Bazán. O traxe rexional galego é obxecto de interese antropolóxico por parte da autora (fundadora da Sociedad del Folk-Lore Gallego en 1883 e promotora do cuestionario do folclore galego de 1885), inclinación que a leva a realizar exhaustivas descricións deste tipo de indumentaria tradicional en obras como La gallega, en contos como Eterna Lei e mesmo na súa novelística máis urbana, representada por La Quimera. O seu gusto polo traxe rexional responde a unha dobre finalidade, ofrecer unha visión antropolóxica da vestimenta popular en Galicia e caracterizar tanto os grupos sociais do rural como algúns personaxes inesquecíbeis como Minia en Un destripador de antaño ou Maripepiña en Bucólica.

Palabras Chave Emilia Pardo Bazán; folclore; traxe galego; indumentaria; Literatura.

ABSTRACT Rural culture, particularly clothing, is an essential narrative element in Emilia Pardo Bazán's literary work. The Galician regional costume is an object of anthropological interest on the part of the author (founder of the Galician Folklore Society, 1883, and promoter of the Galician folklore questionnaire of 1885), a devotion that leads her to carry out exhaustive descriptions of this type of traditional clothing in works like La gallega, in stories like Eterna Ley and even in her most urban novel, represented by La Quimera. Her taste for regional dress serves a double purpose, to offer an anthropological vision of the popular ouffit in Galicia and to characterize rural groups and some unforgettable characters such as Minia in Un destripador de antaño or Maripepiña in Bucólica. KEYWORDS Emilia Pardo Bazán; folklore; Galician regional costume; clothing; literature.

\section{Elementos do traxe rexional: descricións literarias de Pardo Bazán}

A cultura rural, da que a indumentaria é un elemento indiscutíbel, é un tema recorrente tanto na literatura decimonónica como na pintura costumista. Emilia Pardo Bazán participou activamente na recuperación dos costumes populares, as cantigas e a literatura oral e, asemade, do baile e do traxe típico galegos. Baixo a súa presidencia, en 1883 créase na Coruña a Sociedad del 
Folk-Lore Gallego que emprendeu os primeiros traballos sobre etnografía e folclore, cuxo resultado foi o alumeamento dun exhaustivo cuestionario en 1885, Cuestionario del Folk-lore Gallego, establecido en La Coruña el día 29 de diciembre de $1883^{1}$. No citado documento, a epígrafe número 42, "Trajes de hombre que se usan y nombres de sus telas" e a número 46, "Trajes de la mujer actualmente", servíronlle á autora para documentarse e realizar posteriormente as fieis descricións relacionadas co traxe rexional que aparecen tanto en La Tribuna como na obra La Gallega.

Na novela La Tribuna, a través da descrición do vestiario das comparsas de entroido das mozas vestidas de labradores e labradoras galegos o día do domingo de Comadres, a autora revela un extenso coñecemento da indumentaria tradicional dos habitantes do rural:

El Carnaval [...] se distinguió por su animación y bullicio; hubo nada menos que cinco comparsas, todas extremadas y lucidas. Dos eran de mozas y mozos del país, vestidos con ricos trajes que traían prestados de las aldeas cercanas; (...) Las dos de labradores se diferenciaban harto. En la primera se había buscado, ante todo, el lujo del atavío y la gallardía del cuerpo; las cigarreras más altas y bien formadas vestían con suma gracia el calzón de rizo, la chaqueta de paño, las polainas pespunteadas y la montera ornada con su refulgente pluma de pavo real; y para las mozas se habían elegido las muchachas más frescas y lindas, que lo parecían doblemente con el dengue de escarlata y la cofia ceñida con cinta de seda. La segunda comparsa aspiraba, más que a la bizarría del traje, a representar fielmente ciertos tipos de la comarca. Enrollada la saya en torno de la cintura, tocada la cabeza con un pañuelo de lana, cuyos flecos le formaban caprichosa aureola; asido el ramo de tejo, de cuyas ramas pendían rosquillas, estaba la peregrina que va a la romería famosa a que no se eximen de concurrir, según el dicho popular, ni los muertos; a su lado, con largo redingote negro, gruesa cadena de similor, barba corrida y hongo de anchas alas, el indiano, acompañábanle dos mozos de las Rías Saladas, luciendo su traje híbrido, pantalón azul con cuchillos castaños, chaleco de paño con enorme sacramento de bayeta en la espalda, faja morada, sombrero de paja con cinta de lana roja (Pardo Bazán, 2002, p. 172).

1 Unha entrada do Boletín de la Institución Libre de Enseñanza (1885, ano IX, $n^{\circ} 195$ ) asinada por S. explicaba que o cuestionario constaba dos seguintes apartados: I. Galicia e os seus habitantes; II. Idioma e literatura populares; III. Costumes; IV. Festas e calendarios populares; V. Crenzas e supersticións populares; VI. O traballo e as artes populares; VII. Coñecementos populares do fogar; VIII. Do mar. Ademais, a mesma publicación tamén achegaba a seguinte información: "Las cuestiones aparecen muy detalladas y presentadas con suma discreción, constituyendo un trabajo recomendable. Son sus autores los señores don Cándido Salinas, don Antonio y don Francisco de la Iglesia, comisionados para este objeto por la Asociación del Folklore Gallego de La Coruña cuya junta directiva aprobó el cuestionario el 2 de octubre de 1884" (p. 94). 
Neste parágrafo, Pardo Bazán expón este fenómeno de exaltación da sociedade campesiña, da vida rural e dos seus costumes que seducía os habitantes da contorna urbana, incluídas as clases traballadoras. A vaidade tamén está presente na elección dos disfraces, xa que as cigarreiras disfrazadas de labregos pretenden non só facer gala de folklorismo, senón tamén resaltar os seus atributos físicos a través do traxe de gala dos homes en tanto que as disfrazadas de labregas gardan unha maior fidelidade ao traxe rexional feminino, xa de seu favorecedor.

No que respecta aos elementos do traxe masculino mencionados pola autora, cabe destacar o chaleco, peza sen mangas que se colocaba sobre a camisa, definida como unha prenda interior con mangas que cubre o torso e que pode ser de distintas lonxitudes e calidades dependendo de se é para traballo ou de gala (Gómez del Valle, 2016). Ademais, o chaleco podía ir adornado cunha aplicación de pano que se poñía sobre as costas, o sacramento (De Hoyos Sancho, 2010). Outra peza que se destaca é a faixa, normalmente de la, atada á cintura e que servía ao mesmo tempo como peza de abrigo e para suxeitar o calzón. Sobre o chaleco colocábase a chaqueta ou almilla, que era a peza exterior de abrigo do conxunto. $\mathrm{Na}$ parte inferior do corpo lucíase o pantalón ou o calzón, un tipo de pantalón curto que ía dende o abdome inferior até o xeonllo e que levaba botoaduras nos laterais das pernas (Gómez del Valle, 2016).

Moi interesante resulta a mención aos chapeus que locen os homes nesta descrición pardobazaniana de La Tribuna. O texto non menciona en ningún momento o pucho/ pucha ou gorra tradicional, normalmente de la ou pano abatanado, con copa baixa e viseira que se usaba a diario (De Hoyos $\underline{\text { Sancho, }}$ 2010), senón que alude a dúas cubertas diferentes: por unha banda a monteira, unha cobertura para abrigo da cabeza que se facía de pano e cuxa forma variaba de deseño segundo cada provincia. A palabra deriva de monte e, en orixe, era unha peza usada polos montañeses e identificábase cos xornaleiros e outros grupos sociais familiarizados coas tarefas do campo máis fatigosas (Strbáková, 2007).

Doutra banda, o chapeu de fungo que se elaboraba en feltro ou castor e que tiña unha forma chata identifícase na descrición de Pardo Bazán cos emigrantes retornados que adquirían costumes e modas foráneas procedentes dos países dos que volvían. Amais, outro elemento para destacar na vestimenta 
destes indianos é o redingote, un abrigo de orixe inglesa que se usaba en lugar da capa (Strbáková, 2007).

Ademais do seu valor etnográfico, o texto de La Tribuna posúe un innegábel valor narrativo, xa que nestas raparigas ataviadas con roupas de homes apreciamos un implícito afán de equiparación co xénero masculino. As mulleres traballadoras parecen querer dicir ás mozas a través dos seus disfraces que levan o pan ás súas casas de igual xeito que os seus maridos e que en nada se diferenza a dureza dos seus traballos, xa sexa nas faenas agrícolas ou nas fábricas, coa dos que desempeñan os homes, aínda que uns leven pantalóns e outras saias.

La Gallega é un dos relatos/ensaios de Pardo Bazán que recolle de novo os intereses antropolóxicos ${ }^{2}$ da autora en textos tan detallados como o que citamos a continuación, no que dona Emilia realiza unha longa descrición do "gayo traje de las ocasiones solemnes" típico das mulleres de Galicia, sinalando as súas características peculiares en función das zonas:

Si ha nacido en la Mahia, en alguno de los fértiles valles que cercan á Iria Flavia y Compostela, ceñirá á su cabeza, con cinta de vivos tonos, la linda cofia de puntilla transparente. Si en el Ribero de Avia, ó en las cercanías de Orense, llevará el pañolito de seda oscura, que realza la suave palidez del rostro oval, y abrochará atrás el brevísimo dengue con dos conchillas de plata. Si vió la luz en las poéticas orillas de las Rías Bajas ó en Muros, vestirá el rico atavío que enamora á cuantos lo ven: basquiña de claros matices, corpiño de negro raso, ancho mantelo de brillante sedán franjeado de panilla y recamado de azabache, pañuelo de crespón color lacre ó canario, cuyos flecos caen acariciando la cadera airosa, como las ramas del sauce sobre el tronco; rodearán su garganta pesados collares de filigrana de oro, hilos de cuentas, y de su menuda oreja colgarán largos zarcillos, y sobre el pecho refulgirá la patena, conocida por sapo. Pero aun cuando presumen con razón las muradanas, por su elegante arreo, de llevarse la palma en Galicia, pienso que el traje clásico de gallega es el usado por las mujeres de mi país, las mariñanas. Lucen éstas dengue de escarlata orlado de negro terciopelo y sujeto atrás con plateado broche; el justillo, de fuerte drogué $\left.{ }^{3}\right]$, se escota sobre la chambra de lienzo con flojas mangas y puños de curiosa manera fruncidos; el soberbio mantelo no cede en riquezas á otro alguno, y se ata atrás

2 Antón Fraguas Fraguas, en El traje Gallego (1985), alude expresamente a este texto da condesa de Pardo Bazán como referente literario de gran relevancia sobre o tema do traxe rexional.

3 Manuel Alvar (1961-62) sinala que a palabra catalá drogué significa tendeiro en Aragón. Por extensión, o termo podería aludir ao tecido industrial catalán de algodón que se empregaba para elaborar xustillos. 
con cintas de seda de charros colorines; bajo la franja del mantelo se ve media cuarta de saya de grana, y se entrevé un dedo de refajo de amarilla bayeta, y el zapato de cuero con lazadas de galón azul; ciñe su cuello la gargantilla de filigrana, y cubre sus hombros el pañuelo de blanca muselina, prolijamente rameado (Pardo Bazán, 2003, pp. 259, 260).

Pardo Bazán fíxase aquí no traxe de gala ricamente ornamentado que podían exhibir nas festas e romarías as labregas con máis posibilidades. Con todo, veremos que a maior parte do campesiñado galego lucía pobre e atrapallado na súa vida cotiá. Ámbolos dous textos constitúen unha exhibición do gran coñecemento da autora sobre o vocabulario asociado ao traxe típico. Se atendemos á vestimenta feminina podemos apreciar algúns dos elementos máis distintivos do que hoxe coñecemos como traxe de galega. $\mathrm{O}$ dengue, en primeiro lugar, era unha peza que ía sobre os ombreiros cruzada sobre o peito e que se suxeitaba por detrás con cintas ou broches como as dúas "conchillas" de prata mencionadas pola autora. Esta peza foi substituída progresivamente ao longo do século XIX pola chaqueta e polo mantón de Manila ou da China, costume que non foi moi do agrado da tradicionalista dona Emilia. De feito, a autora critica a substitución de pezas da indumentaria popular e típica por outras de influencia foránea:

A las sayas de grana y bayeta, el faldellín de estampado percal francés; al dengue, el mantón; á las trenzas,la moña tamaña como un rosquete de pan; al villanesco zapato de cuero la bolita de rusél... y en breve será preciso internarse hasta el corazón de las más recónditas y fieras montañas para encontrar un tipo que tenga olor, color y sabor genuinamente regional (Pardo Bazán, 2003, p. 260).

O dengue escarlata orlado de veludo que describe en La gallega denota que o traxe do que fala está destinado a un uso festivo dada a calidade e luxo dos materiais e cores empregados que non eran habituais se o traxe era de feira. Antón Fraguas (1985, p. 40) recolle unha estampa dunha anciá que vai camiño da romaría cunha vela na man e ben ataviada co seguinte fragmento, atribuído a Antonio Noriega Varela:

A unha vella de cen anos

que entre un fato de peisanos

pasou prá misa, ¡bai que vela!:

leva dengue colorado

$i$ on cirio repinicado

feito de cera amarela. 
O xustillo ou corpiño era unha peza sen mangas, reforzada con baleas, destinada a realzar a figura e que, destinado a días de gala, podía ser de materiais moi finos, como o raso que a autora menciona (Gómez del Valle, 2016). A chambra, faldra ou cós era unha peza semellante á camisa pero con puños axustados e mangas anchas que se decoraba con encaixes en pescozo, puños e peito e que, por tanto, tamén se reservaba para as ocasións especiais. Normalmente, como a autora indica, fabricábase de lenzo ou liño. Sobre a camisa colocábase o refaixo, que se confeccionaba en la ou baeta se era para diario, e que podía ir orlado de veludo nos traxes festivos. A saia ía sobre o refaixo ${ }^{4} \mathrm{e}$ chegaba até os nocellos, salvo se se trataba da saia capada, que era máis curta por ser a de traballo.

Pola súa banda, a vasquiña era unha saia exterior ben cinguida á cintura e de ancho voo que, no caso das muradás, é de cores claras. O mantelo era unha especie de mandil ou saia aberta, acampanada, de pano e ornada de veludo e acibeche que en toda Galicia se poñía sobre a saia para as festas. A cofia ${ }^{5}$ típica das compostelás era unha toca branca de encaixe ou batista que colgaba por detrás e onde as mulleres metían a trenza (De Hoyos Sancho, 2010).

En canto aos adornos que a autora nos describe, o aderezo por excelencia era o sapo, coñecido tamén como filigrana de Padrón, porque este é o lugar onde se fabricaban xunto con Noia e Santiago. O sapo constaba de dous ou tres corpos. O superior tiña forma de cola de pavo real aberta e unha trama de fíos moi finos ou cintas con raias ou lisas con pequenas placas en forma de media laranxa. O segundo corpo podía ser en forma de crecente ou trapezoidal e a terceira era triangular cunha media laranxa, aínda que ás veces este terceiro tramo tamén presentaba forma de corazón. O sapo ía combinado con abelorios longos formados por dous ou tres corpos unidos por unha cinta que formaba a argola de articulación. Tamén eran frecuentes os pendentes en forma de aro, morcilla ou media lúa. Estes adornos usábanse en ocasións moi especiais como vodas e romarías e normalmente eran de prata. Cando se lucían aros de ouro falábase do traxe rico ou traxe de rica que, normalmente, identificaba a unha campesiña con recursos (Fraguas y Fraguas, 1985).

4 Antón Fraguas $(1985$, p. 38) recolle unha cantiga popular sobre esta prenda: "Salerosa, romenda o refaixo / que o levas roto por riba e por baixo; / por riba e por baixo, por baixo e por riba; / salerosa, romenda a mantilla".

5 Fraguas $(1985$, p. 40) recolle outra cantiga popular sobre algúns destes elementos do traxe rexional: "Estira a cofia, Maruxa, / dobra as mangas da camisa / para que o denguiño se luza". 
Este traxe luxoso constituía un prezado tesouro e era gardado con mimo polas súas posuidoras en arcas das que non se sacaba se non se trataba de ocasións especiais como ir á festa, á misa ou á feira. A importancia da roupa residía na súa consideración como un ben patrimonial familiar que se conservaba coidadosamente nas arcas para que a herdasen as xeracións futuras (SáenzChas Díaz, 2014; Fraguas y Fraguas, 1985), do cal dá conta o conto De polizón:

¡Cuánto conocía yo ese mueble familiar de nuestros aldeanos, donde guardan lo que más estiman! Allí se encierran, entre espliego, «lesta» y olorosas manzanas, el «dengue» majo, la randada camisa de lino, el «paño» de seda y los brincos de filigrana de plata, galas que sólo salen a relucir el día de fiesta del patrón; allí, en el pico, se esconden, dentro de una media de lana, los ahorros que tantas privaciones presentan, desde el amarillo centén hasta el roñoso ochavo «de la fortuna» (Pardo Bazán, 1990, tomo II, p. 86).

Se lembramos a escena do entroido de La tribuna podemos constatar que, en ocasións, as descendentes, fillas ou netas das titulares de tan prezada posesión, acababan por reutilizar os traxes dos seus avós e das súas avoas para disfrazarse de labregos en comparsas de carácter folclórico. Esta idea é moi interesante, xa que demostra a orixe rural de gran parte do proletariado urbano galaico que, aínda abandonando o campo, non abandonaba as súas esencias ${ }^{6}$.

\section{Visións literarias do traxe típico: da preservación á idealización}

O interese antropolóxico de Emilia Pardo Bazán lévaa a preocuparse en reiteradas ocasións pola preservación da indumentaria tradicional ${ }^{7}$. O traxe

6 Tampouco debemos perder de vista que en Galicia as provincias costeiras da Coruña e Pontevedra, así como as súas capitais (Marineda), eran os principais focos de atracción do éxodo rural, xa que eran moito más puxantes economicamente que as do interior (Moya, 1995).

7 No citado cuestionario, a epígrafe número 43, "Recuerdo de trajes antiguos: sayos y capotes, camisas y cirolas, chaleques y escapularios, calzones y fajas, polainas y botines, monteras y sombreros, madreñas y zocos, borceguíes y zapatos, pañuelos y tangalejos ó tabaqueiros, aretes de algunos, mócas, palos, bisarmas y cardeñas", e a número 47, "Recuerdo de antiguos trajes y de su tocado y adornos: la camisa y enaguas, las corbatas y justillos, las figas, amuletos y medallas, los dengues y las parlamentas, los pañuelos y cofias, los mantelos ó rianjos y refajos, los guardapiés y las sayas, el calzado y sus hebillas, los aderezos de cruz y pendientes, otras joyas como las sortellas, los anelos, aros y cabazas", permitirán á autora ter constancia sobre os cambios introducidos na indumentaria popular e de aí a súa preocupación e as súas críticas sobre o tema. Amais, Belén Sáenz-Chas Díaz (2014) sinala que os produtos téxtiles europeos chegaban a Galicia con gran facilidade debido a que a burguesía galega do XIX fixo fortuna coa actividade comercial. O comercio permitiu incorporar á indumentaria popular o damasco, a seda, a casimira e o veludo. Probablemente estes cambios, que foron tan ben acollidos no seu momento polas aldeás galegas, son os que tan pouco gustan aos puristas do traxe tradicional como Emilia Pardo Bazán. 
rexional estaba a desvirtuarse progresivamente, entre outros motivos, porque a finais do XIX a burguesía afeccionouse ás fotos folclóricas e empezou a lucir elementos característicos da indumentaria popular rural ${ }^{8}$ (dengues, mantelos, panos na cabeza) como aderezos que dotaban os seus vestidos dun toque pintoresco.

Debido ao afán de emulación das clases baixas, ocorreu que moitos campesiños asumiron elementos da vestimenta típicos da condición burguesa e abandonaron outros tradicionais. Algúns exemplos deste transvasamento constatado por dona Emilia atópanse en La Gallega, onde recolle detalladamente esta asunción de modas mesocráticas que corrompían a vestimenta do campesiñado galego:

A las sayas de grana y bayeta, el faldellín de estampado percal francés; al dengue, el mantón; á las trenzas,la moña tamaña como un rosquete de pan; al villanesco zapato de cuerola bolita de rusél... y en breve será preciso internarse hasta el corazón de las más recónditas y fieras montañas para encontrar un tipo que tenga olor, color y sabor genuinamente regional (Pardo Bazán, 2003, p. 260).

Eterna Ley é outro exemplo onde critica a desnaturalización da vestimenta 12 popular:

Llevaba al hombro la chaqueta parda; su chaleco era rojo, sus pantalones de pana aceituna. Aunque no vestía rigurosamente el traje del país, que cada día va perdiéndose, y aunque en lugar de la montera picuda con su airón de pluma de pavo real, cubriese su cabeza la vulgar boina, era una aparición en extremo típica (Pardo Bazán, 1990, tomo III, p. 270).

Mesmo no conto Que vengan aquía autora non pode evitar aludir á perda da pureza das tradicións, aínda que sexa de esguello: “Tal vez sea Rezois el punto de Galicia donde se conservan más fielmente el traje regional y las costumbres añejas" (Pardo Bazán, tomo II, p. 49).

Pardo Bazán tamén recolle o interese da pintura costumista por retratar o traxe típico rexional. É o caso do personaxe de Silvio Lago en La Quimera, pintor que, a pesar das súas ansias cosmopolitas, non escapa á proliferación

8 O conto Curado recolle, por exemplo os elementos máis identificativos do traxe rexional feminino, o mantelo e as zocas: "Aún no blanqueaba el alba, anunciándola tan sólo vago reflejo cárdeno hacia el bosque, cuando salió la mujerona, arrebujada la cabeza en su mantelo de burel, haciendo saltar barro líquido jflac!, jflac! de los charcos, al hincar en ellos las enormes zuecas" (Pardo Bazán, 1990, tomo II, pp. 318-319). 
deste estilo pictórico folclorista que plasma nunha das súas primeira obras: Recolección de la patata en la Mariña. Lago, como tantos pintores da súa época, retrata os temas que demanda a súa potencial clientela burguesa, pero a escena que representa non pode considerarse un fiel reflexo da realidade porque está inspirada nunha idealización romántica da sociedade campesiña. Ademais, se temos en conta a forma en que este tipo de obras se elabora, apréciase en maior medida a perda de contacto coa realidade. O pintor tomaba primeiro apuntamentos do natural e despois executaba a obra no estudo. Neste proceso podía investir un longo tempo. O intervalo transcorrido favorecía a evocación edulcorada dunha Galicia soñada que pouco tería que ver coa realidade socioeconómica da época ${ }^{9}$. As palabras de Silvio deixan moi claro o carácter de ficción pictórica da obra:

Este cuadro puedo decir que lo tengo en apuntes, en notas tomadas directamente, aldeanas. Al volver a verlas, después de tanto tiempo y tan lejos de donde las recogí, ¡qué alegría! -me parecen fuertes y sinceras. La vieja que se cubre con el paraguas de algodón azul; la mozallona que se inclina al suelo marcando sus groseras formas; ....Y los colores chillones de las ropas, y el verde insolente de la vegetación, y el cielo brumoso y la augusta verdad (Pardo Bazán, 1991, pp. 207, 208).

Esta visión edulcorada repítese en La madre Naturaleza cando o recentemente chegado don Gabriel observa estoutra amábel estampa literaria infestada de alegres cantigas e de vestimentas de característico colorido: "Sobre el fondo oscuro de la tierra vio blanquear las camisas y sayas, las fajas rojas y los pañuelos azules de labriegos y labriegas; contra un matorral descansaba un jarro de barro, y la cuadrilla, entonando su inevitable ¡ay... le le!” (Pardo Bazán, 1999, p. 267).

\section{A vestimenta real dos labregos: luxos campesiños}

Moitas son as obras ambientadas no rural nas que Pardo Bazán se fai eco dos modos de vestir dos aldeáns galegos e que ofrecen unha caracterización

9 Fernando Álvarez de Sotomayor (1875-1960), pintor de referencia para o estudo do traxe rexional, retrata sempre escenas agradábeis, idealizando os personaxes e evocando rostros amables e apracíbeis, como no óleo sobre lenzo Estudio para Romería (1904-1906), que pertence ao catálogo do Museo Provincial de Belas Artes de A Coruña e pode visualizarse no seguinte enlace: http:// museobelasartescoruna.xunta.gal/index.php?id=392\&idc=5960. Ademais, tamén resulta de especial interese o estudo Do Neoclasicismo a 1950 (1993), de Xosé Manuel López Vázquez (incluído no volume Galicia Arte, Tomo XV, Arte Contemporáneo, publicado por Hércules). 
non só etnográfica, senón tamén social, da condición campesiña a través da súa vestimenta ${ }^{10}$. En numerosos relatos se transloce a pobreza do vestiario da maioría dos campesiños, máis aínda se son xornaleiros. Certifica esta idea a reflexión que fai o tío de Minia en Un destripador de antaño: "El bienestar! Para un labriego... distingue al labrador acomodado del desvalido. Después viene el lujo de la indumentaria” (Pardo Bazán, 1990, tomo II, p. 8).

A pompa da indumentaria queda restrinxida, como xa vimos, aos días de festa ou a certas pezas. A roupa do día a día arranxábase, zurcíase, remendábase e adaptábase aos cambios da cintura froito de embarazos ou flutuacións de peso. Tamén se lle daba a volta e, cando xa non daba máis de si, desfacíase en tiras para que a tecesen as farrapeiras ${ }^{11}$. Por regra xeral, a miserábel condición do campesiñado foreiro ou xornaleiro galego vese reflectida nos seus farrapos. A Sabia ${ }^{12}$ e as xornaleiras de La madre Naturaleza son representativas desta afirmación:

La horrible vieja ya habia dejado su camastro; pero(...), estaba sin pañuelo ni justillo, en camisa, con sólo un refajo de burdo picote, ribeteado de rojo: los copos de sus greñas aborrascadas le cubrían en parte el negro pescuezo, sin ocultar la monstruosa papera (Pardo Bazán, 1999, p. 271).

Las jornaleras, vestidas con sayas angostas de zaraza desteñida, que les señalan los recios muslos, sacuden la paja, la colocan en rimeros grandes, preparan la camada nueva... (Pardo Bazán, 1999, p. 314).

Tamén pobremente vestida enxuga o seu pranto a tía Antonia do relato Atavismos, "con el pico del pañuelo de talle, andrajoso", quen descalza e con greñas "luce el luto desteñido y pardusco de los pobres” (Pardo Bazán, 1990, tomo III, p. 243).

10 Emilia Pardo Bazán é un exemplo paradigmático de como a vida cultural permite interpretar obxectos, espazos, normas e accións como portadores dun mundo invisíbel cheo de significados, sobre o cal escribe José Antonio Fernández de Rota y Monter no artigo "Evocación antropológica de la novelística de la condesa de Pardo Bazán" (2005).

11 Belén Sáenz-Chas Díaz (2014) recolle o caso dos mandís dunha familia de Lousame, feitos dunha antiga chaqueta de meiriño e veludo, desmontada e aproveitada na década dos 40 do século XIX para a confección de dous pequenos mandís cos que vestir a dúas nenas de pastoras galegas na festa da Árbore.

12 A Sabia de Los pazos de Ulloa responde ao catálogo de personaxes característicos do folclore galaico, tal e como se recolle na epígrafe 246 do cuestionario do folclore: "Sabias. Modos de echar las cartas. Adivinación de sueños, destino, cosas perdidas, secretos, etcétera. Aparición de personas en el agua de una redoma ó botella". 
Asemade, moi humilde é a indumentaria das dúas aldeás coas que Rojo se tropeza en La piedra angular, "una niña y una mujer del pueblo, modestamente trajeadas, que se quedaron mirándole de hito en hito" (Pardo Bazán, 1999, tomo III, p. 437). A roupa interior non escapa a esta miseria xeneralizada e de basta estopa é a recia camisa de Minia en Un destripador de antaño (Pardo Bazán, 1990, tomo II, p. 6).

Pola súa banda, a feirante do conto Cuesta abajo esconde o diñeiro da venta duns leitóns entre "un justillo de estopa y el ajustador de caña" (Pardo Bazán, 1990, tomo II, p. 327). Tamén é de caña o axustador de La capitana, relato no que se acredita o típico que é entre as galegas a vestimenta desta prenda íntima:

No quisiera que os representaseis a Pepona de una manera falsa y romántica, con el terciado calañés y el trabuco de Carmen, ni siquiera con una navaja escondida entre la camisa y el ajustador de caña que usaban por entonces las aldeanas de mi tierra (Pardo Bazán, 1990, tomo II, p. 344).

Pardo Bazán recollía a dura realidade da emigración como única saída posíbel da que dispoñía o campesiñado galego para prosperar nos relatos $D e$ polizón e en El tetrarca de la aldea. Como indica Fernando Devoto en Historia de la inmigración en la Argentina (2003), a emigración a América á que aluden ámbolos dous relatos viuse favorecida polo desenvolvemento dos buques de vapor, o abaratamento dos prezos da pasaxe e a mellora das condicións hixiénicas e sanitarias da viaxe, especialmente dende 1870. Unha vez máis, Emilia Pardo Bazán testemuña fielmente nos seus relatos a realidade socioeconómica do campesiñado da época.

De feito, a marcha do patriarca da familia de El tetrarca de la aldea serve para mellorar as condicións de vida dos seus incluso no relativo á indumentaria:

Nunca Sabel habia vestido de lana rasa como entonces, ni calzado rico borcegui de becerro, ni usado tan finas ropas como las que se entreparecían al través del justillo aún desabrocbado.¿Recordó Marcos que al partir él quedaba desnuda y hambrienta su familia? (Pardo Bazán, 1990, tomo II, p. 65).

Algunhas campesiñas locen unha vestimenta máis pulcra e mesmo se adornan con xoias ${ }^{13}$. A orixe destes pequenos luxos pode ser honesto, como o

13 Recordemos o catálogo de xoias populares que recollía a epígrafe 47 do cuestionario do folclore: "las figas, amuletos y medallas, [...] los aderezos de cruz y pendientes, otras joyas como las 
diñeiro enviado por aquelas cabezas de familia emigradas ou os aforros propios, rabuñados con esforzo, como ocorre no caso dos "pendientes de prehistórica forma” da muiñeira de La madre Naturaleza (Pardo Bazán, 1999, p. 251). Menos honorábel é a procedencia dos esplendores das aldeás que contan cun protector como Sabel, a amante de don Pedro Moscoso, vestida con "innumerables sayas" (Pardo Bazán, 1999, p. 224) en La madre naturaleza, e que se adorna con pendentes en Los pazos de Ulloa; tamén estaría a "modistiña" de La mayorazga de Bouzas, que loce aros de ouro regalo do seu señor. En efecto, os xogos de poder derivados da organización socioeconómica do rural baseada nas complexas redes clientelares de dependencia e nos mecanismos de pago xerados polos sistemas de foros e arrendamentos dos que fala José Antonio Fernández de Rota y Monter (2005) vense reflectidos na submisión sen resistencia destas mulleres aldeás perante os desexos dos fidalgos dos que dependía o benestar propio e das súas familias. Os agasallos que reciben son o signo do seu sometemento.

Pero o fasto da indumentaria que estrañaba o tío de Minia en Un destripador de antaño vese reflectido na vestimenta rural feminina, non tanto a través das alfaias, senón mediante a exhibición dun pano de seda. Esta peza gozou de gran predicamento entre as aldeás e a súa posesión era un signo de triunfo. Así o di expresamente Cipriana, mariscadora de doce anos protagonista de El pañuelo:

El pañuelo es la gala de las mocitas en la aldea, su lujo, su victoria. Lucir un pañuelo majo, de colorines, el día de la fiesta; un pañuelo de seda azul y naranja... ¿Qué no haría la chicuela por conseguirlo? Su padre se lo tenía prometido para el primer lance bueno; iy quién sabe si el ansia de regalar a la hija aquel pedazo de seda charro y vistoso había impulsado al marinero a echarse a la mar en ocasión de peligro (Pardo Bazán, 1990, tomo III, p. 225).

La madre naturaleza certifica que o pano é o adorno ideal para embelecer a muller campesiña e mesmo Pardo Bazán identifica a dozura de carácter das aldeás galegas coa suavidade do tecido de seda:

sortellas, los anelos, aros y cabazas". Tamén a epígrafe 60 recolle: "Perforación de las orejas. Aretes en ambos sexos". A este respecto, resulta especialmente interesante a fotografía dunha anciá campesiña con aros titulada Unha muller labrega. Santa Eulalia de Camos, capturada en Nigrán no 1926 por Ruth Mathilda Anderson. Esta imaxe está recollida na páxina 339 do catálogo das fotografías que Anderson realizou durante as súas viaxes por Galicia entre 1924 e 1926, publicado no 2009 pola Fundación Caixa Galicia de A Coruña en asociación con The Hispanic Society of America, con ensaios realizados por Patrick Lenaghan, Miguel Anxo Seixas Seone e Ramón Villares. 
Tray un pañuelo de seda, mujer... -murmuró su esposo-. Hay que hacerle un sostén para el brazo malo. Con prontitud y no sin gracia se quitó Catuxa el que llevaba a la garganta, que era carmesí con lista negra, y ella misma lo ató al cuello del forastero, diciendo mimosamente, con suavidad del todo galiciana:¿Queda así a gustiño, señor?. Don Gabriel agradeció sonriendo. El diminutivo, el calor de la seda que había estado en contacto con la piel de la arrogante moza, le produjeron el efecto de una caricia del país natal (Pardo Bazán, 1999, p. 150).

O pano servía ás aldeás para protexer o pescozo e para cubrir e adornar a cabeza. Emilia Pardo Bazán tamén se ocupou do peiteado característico das mulleres do rural: as dúas trenzas, escondidas normalmente baixo o inevitábel pano de seda ou algodón. Numerosas son as raparigas dos seus relatos que levan así recollido o seu cabelo: a nena Dalinda, protagonista do relato que leva o seu nome por título, quen lucía "dividido en dos trenzas el hermoso pelo rubio" (Pardo Bazán, 1990, tomo II, p. 328); a humilde "tecelana” de El voto de Rosiña, con "un apretado haz de rayos de sol en la trenza doble que colgaba hasta sus caderas" (Pardo Bazán, 1990, tomo II, p. 160); pola súa banda, a costureira de La mayorazga de Bouzas cobre cun pano azul as súas dúas "largas trenzas colgantes” (Pardo Bazán, 1990, tomo II, p. 26).

Outras raparigas locen o pelo solto e alisado con auga, único afeite que poden permitirse as mulleres pobres e traballadoras. En Lumbradrada atopamos o caso da leñadora Camila Moñobre, quen exhibe un "pelo negro, alisado con agua e indómito” (Pardo Bazán, 1990, tomo III, p. 205).

\section{A vestimenta da inocencia e da picardía: Minia e Maripepiña}

No terríbel relato Un destripador de antaño, Pardo Bazán fai uso da vestimenta e o peiteado campesiños como un recurso dramático fundamental. Primeiro ofrécenos un retrato entenrecedor da personaxe da infeliz Minia, desprezada pola súa familia, que se nos presenta como unha heroína shakespeariana a través do seu peiteado ${ }^{14}$ :

El pelito envedijado y revuelto y a veces mezclado -sin asomo de ofeliana coquetería-con briznas de paja o tallos de los que segaba para la vaca en los linderos de las heredades (Pardo Bazán, 1990, tomo II, p. 6).

14 A descrición de Minia no texto de Pardo Bazán evoca a obra Ofelia do prerrafaelita John Everett Millais, que a representa morta co cabelo solto e rodeada de flores río abaixo (Sabel Gabaldón, 1852; Ana Peluffo, 2004 e Michael Gibson, 2006). 
A pastora carece de luxo algún e o desprezo dos seus familiares tradúcese en que vai vestida con farrapos: "Minia cubría sus carnes con un refajo colorado, desteñido ya por el uso; recia camisa de estopa velaba su seno, mal desarrollado aún; iba descalza" (Pardo Bazán, 1990, tomo II, p. 6). O destino que a súa familia dispuxo para ela é o de desempeñar as tarefas máis viles en tanto que "su prima Melia, destinada por su madre a costurera, que es entre las campesinas profesión aristocrática, daba a la aguja en una sillita, y se divertía oyendo los requiebros bárbaros y las picardihuelas de los mozos y mozas que acudían al molino" (Pardo Bazán, 1990, tomo II, p. 8). Minia é maltratada psicoloxicamente pola súa tía e fisicamente polo seu tío, quen emprega como arma para ferila unha dura zoca de madeira: "La niña recibía los golpes con estoicismo, palideciendo a veces cuando sentía vivo dolor -cuando, por ejemplo, la hería en la espinilla o en la cadera la punta de un zueco de palo-, pero no llorando jamás" (Pardo Bazán, 1990, tomo II, p. 9). A rapariga é obxecto de humillacións por parte da súa familia porque, a pesar de todas as súas privacións, é fermosa e ofrece unha imaxe limpa e pulcra que evoca a súa pureza moral. Como antítese, Pardo Bazán constrúe a personaxe da súa tía, a Pepona, unha muller agreste, sucia, groseira, cuxa animalidade queda retratada porque se lava "primero los pies y luego la cara en el charco más próximo 18 a la represa del molino" (Pardo Bazán, 1990, tomo II, p. 11). A Pepona anda desaseada e descalza pero avíase para visitar ao rendeiro e pedirlle un favor poñéndose "el dengue y el mantelo de los días grandes y también -lujo inaudito- los zapatos” (Pardo Bazán, 1990, tomo II, p. 11).

O mantelo é tamén a peza que delata o horríbel crime que os brutais parentes de Minia cometen e, por riba, o único luxo no vestir da rapariga, mais xa despois de morta ${ }^{15}$ : "Un «mantelo» tosco cubría la mutilación de las despedazadas y puras entrañas; sangre alrededor, desleída ya por la lluvia, las hierbas y malezas pisoteadas, y en torno, el gran silencio de los altos montes y de los solitarios pinares...” (Pardo Bazán, 1990, tomo II, p. 20).

Moi distinta da inocente Minia é a pícara Maripepiña do relato Bucólica. Emilia Pardo Bazán descríbea como exemplo encarnado do catálogo de características físicas típicas da galega analizados a partir do cuestionario do folclore de 1885, e dela di que, ademais de andar descalza:

${ }^{15}$ A morte de Minia para extraerlle as entrañas e facer feitizos cos que procurar boa sorte á súa familia forma parte das "Creencias referentes a la virginidad, a sus signos, valor moral..." das que se ocupaba a epígrafe 267 do cuestionario do folclore galego. 
Maripepiña es de mediana estatura, tiene el cutis asoleado, sembrado de pecas, rojo el greñudo cabello, las manos oscuras y curtidas, con uñas cuadradas y romas, el pié muy ancho y plano, sin duda por la costumbre de no calzarse sino los días festivos, y de pisar cantos y asperezas. Tú, que te mueres por un pié bonito encerrado en elegante bota, tendrías para reirte un mes con la ancha base de esta criatura (Pardo Bazán, 2003, pp. 71-72) ${ }^{16}$.

A agreste protagonista de Bucólica é a representación das virtudes campestres que seducen o protagonista. Sucumbir aos encantos de Maripepiña é o natural tendo en conta a encantadora presenza que exhibe en cada unha das súas aparicións. Sexa descalza ou arranxada e calzada convenientemente, a rapariga resulta atractiva pola súa frescura e naturalidade ${ }^{17}$ :

¡También ella se babía pulido y arreglado á su modo!' Llevaba mantelo negro, liso y muy ceñido, con ancha cenefa de pana; dengue negro también, recamado de azabache y sujeto á la cintura con un broche de dosconchitas de plata relucientes; al cuello, pañolito de seda azul. Su pelo rojo, alisado con agua, tenía al sol reflejos cobrizos, y su tez, á fuerza, sin duda, de fricciones, ostentaba un brillo de juventud; las pecas satinaban á trechos el cutis tostado, y los ojos, verdosos, parecían de metal, vistos á la claridad del día (Pardo Bazán, 2003, p. 88).

O namorado Joaquín Vermellas observa a rapariga cunha mirada indulxente seducido pola súa aparencia sa e os seus modais suaves e tenros. Maripepiña é a natureza amable. O galán vese atrapado polo seu influxo silvestre até o punto de atopar todas as virtudes imaxinábeis na contorna que rodea a Maripepiña. Tan encandeado está que mesmo atopa digna de acesos eloxios unha das pobres pezas típicas do rural só porque forma parte da vida cotiá da súa amada ${ }^{18}$ :

¡Yo me había venido sin el impermeable! Al punto envió á su casa el notario por una prenda que aquí se usa mucho: la capa de paja. Estos impermeables rústicos

16 Ver epígrafes do cuestionario número 50, "Estatura general"; 51, "Color del pelo: tez pecosa o sin pecas; tamaño del pie y de la mano: abundancia de vello: pómulos abultados o no"; 52, "pelo rizoso ó lacio: color de los ojos: color de los labios: frentes chatas ó prolongadas: oreja grande ó chica: cintura ancha ó delgada: caderas anchas ó estrechas"; e 53, "Forma del pie, si tiene arco ó puente ó es plano: modo de andar; si hay balanceo al moverse: barba, si abunda ó son los hombres generalmente lampiños".

17 Ir descalza foi habitual entre o campesiñado galego até ben entrado o século XX, do cal dá mostra outra das fotografías de Anderson recollida no catálogo xa mencionado (2009, p. 232) e titulada Colocando a carga sobre a cabeza da muller, realizada en Padrón no 1924.

18 A descrición do relato remítenos á epígrafe 45 do cuestionario do folclore galego: "Impermeables de junco: capas y corozas o caperuzas". 
dan excelente resultado, pues sobre la superficiede las pajas resbala el agua, sin que entre una gota: nada pesan, y aislan por completo de la humedad: tienen capucha y cubren todo el cuerpo (Pardo Bazán, 2003, pp. 91-92).

Pero a protagonista de Bucólica non é tan pura, inxenua e inocente como aparenta. Maripepiña non ama o seu galán e o señorito verase desairado pola aldeá, quen acabará por casar cun mozo da súa elección deixando o seu pretendente cos fociños dunha cuarta. En efecto, Pilar González Martín en Aporías de una mujer, Emilia Pardo Bazán (1998) explica que a autora reivindica para a muller a liberdade de elección de cónxuxe. O matrimonio debe ser por amor e a muller non debe inmolarse nun matrimonio non desexado. Maripepiña é a máxima expresión desta idea aínda cando isto implica desairar as expectativas do seu señorito.

En Bucólica, a natureza rise da civilización. O campesiño sometido e abusado polo señor atopará en Maripepiña unha eficaz vingadora dos seus pesares. Bucólica, segundo dixo Paredes Núñez (1979), é unha verdadeira réplica do tema horaciano onde o home de cidade resulta ser un inxenuo fronte á moza campesiña que el cre inocente e candorosa. Co personaxe de Maripepi-

20 ña todas as mulleres do rural menosprezadas e intimidadas durante xeracións polos caciques burlan aos seus burladores.

\section{Conclusións}

Na obra literaria de Emilia Pardo Bazán, a escritora deixa clara a súa enorme erudición en materia de indumentaria popular típica galega. A autora, como acabamos de ver, describe nas súas novelas e relatos os elementos fundamentais da vestimenta tradicional e dá conta do seu intenso labor de documentación etnográfica a través de detalladas descricións.

Pardo Bazán amosa nalgúns dos seus relatos unha visión un tanto roussoniana da Galicia rural e, tal vez por iso, defende a pureza e a preservación da vestimenta sen intromisións de elementos da indumentaria urbana ou das tendencias de moda. Non obstante, como fai naquelas obras nas que se adscribe á corrente do naturalismo literario, a visión escura e decadente que ofrece do ámbito rural trasládase á vestimenta desastrada e pobrísima da maioría das súas personaxes. 
O realismo, ás veces desagradábel, que exhibe en obras coma a serie das novelas dos pazos non impide amosar certos detalles do luxo que se podían permitir as clases campesiñas. Os panos, as pequenas xoias ou os caprichos no peiteado son mostra deste afán dos habitantes do rural por aparentar e, incluso, emular os fidalgos.

Finalmente, Pardo Bazán realiza a través de elementos da indumentaria e do peiteado caracterizacións magníficas de mulleres coma Minia, personificación da inocencia malograda, ou Maripepiña, encarnación da malicia dos desfavorecidos. Con estes arquetipos a escritora coruñesa deixa constancia da súa enorme habilidade para empregar a roupa e o adorno como un recurso literario de primeira categoría.

\section{Bibliografía}

Alvar, M. (1961-1962). Léxico catalán en tierras aragonesas. Atlas Lingïistic de Catalunya, AFA, 12-13.

De Hoyos Sancho, N. (2010). El traje regional de Galicia. CSIC-Grupo Etnográfico das Mariñas.

Devoto, F. (2003). Historia de la inmigración en la Argentina. Editorial Sudamericana.

Fernández de Rota y Monter, J. A. (2005). Evocación antropológica de la novelística de la condesa de Pardo Bazán. Revista de dialectología y tradiciones populares, LX (1), 123-139. DOI http://dx.doi.org/10.3989/rdtp.2005.v60.i1.120

Fraguas y Fraguas, A. (1985). El traje Gallego. Fundación Pedro Barrié de la Macia.

Gabaldón, S. (2014). "Ofelia” de John Everett Millais (1852). Temas de psicoanálisis, 7. https://www.temasdepsicoanalisis.org/hemeroteca/numero-7-enero-2014/

Gibson, M. (2006). El Simbolismo. Taschen.

Gómez del Valle, P. (2016). Traxes na Galiza: Fotografías de Paula Gómez del Valle. Cunca Editora.

González Martín, P. (1998). Aporías de una mujer: Emilia Pardo Bazán. Siglo XXI.

Moya, J. C. (1995). La fiebre de la emigración: el proceso de difusión en el éxodo trasatlántico español 1850-1930. En J. De Juana e X. Castro (Eds.), VII Xornadas de Historia de Galicia. Cuestións de Historia galega (pp. 177-201). Deputación Provincial de Ourense. 
Pardo Bazán, E. (1990). Cuentos completos [tomos I, II, III, IV]. Fundación Pedro Barrié de la Maza Conde de Fenosa [Edición de Juan Paredes Núñez].

Pardo Bazán, E. (1991). La Quimera. Cátedra [Edición de Marina Mayoral].

Pardo Bazán, E. (1997). Los pazos de Ulloa. Cátedra [Edición de Ma Ángeles Ayala].

Pardo Bazán, E. (1999). La madre naturaleza. Cátedra [Edicion de Ignacio P. López].

Pardo Bazán, E. (2002). La tribuna. Alianza [Edición de Marisa Sotelo Vázquez].

Pardo Bazán, E. (2003). Obras completas VII. La dama joven. Cuentos escogidos. Cuentos de Marineda. Biblioteca Castro [Edición de Darío Villanueva y José Manuel González Herrán].

Paredes Núñez, J. (1979). Los cuentos de Emilia Pardo Bazán. Universidad de Granada.

Peluffo, A. (2004). Latin American Ophelias: The Aesthetisation of Female Death in Nineteenth-Century Poetry. Latin American Literary Review, 32(64), 63-78. www.jstor.org/stable/20119929

S. (1885). Bibliografía. Cuestionario del Folk-lore Gallego (I). Boletín de la Institución 22 Libre de Enseñanza, IX (195), 94. http://pares.mcu.es/ParesBusquedas20/catalogo/show/6099833

Sáenz-Chas Díaz, B. (2014). Folclorización e estudos de indumentaria en Galicia. ADRA: revista de los socios y socias del Museo del Pueblo Gallego, 9, 41-55. http:// www.museodopobo.gal/web/revista-adra.php?lang=es

Sociedad del Folk-lore Gallego (1885). Cuestionario del Folk-lore Gallego, establecido en La Coruña el día 29 de diciembre de 1883. Establecimiento Tipográfico Ricardo Fé. http://biblioteca.galiciana.gal/pt/consulta/registro. $\mathrm{cmd}$ ? id=5279

Strbáková, R. (2007). Procesos de cambio léxico en el español del siglo XIX: el vocabulario de la indumentaria [tese de doutoramento]. Universidade de Granada. https:// digibug.ugr.es/handle/10481/1671 